\title{
Ensino em ciências e educação para o patrimônio: uma fusão metodológica para o ensino de Química, a preservação patrimonial e a alfabetização científica
}

\author{
The teaching of science and heritage education: \\ a methodological fusion for Chemistry teaching, heritage \\ preservation and scientific popularization
}

Thiago Sevilhano Puglieri ${ }^{1}$ https://orcid.org/0000-0002-2570-6507 Diego Lemos Ribeiro ${ }^{1}$ https://orcid.org/0000-0002-2433-4828 Daniel Mauricio Viana de Souza ${ }^{1}$ https://orcid.org/0000-0001-8767-7169

Carla Gastaud ${ }^{1}$ https://orcid.org/0000-0003-4314-5595

Alzira Yamasaki ${ }^{2}$ https://orcid.org/0000-0001-9200-6212 Patrícia Santos Schneid ${ }^{3}$ https://orcid.org/0000-0003-0828-5752

\begin{abstract}
Resumo: Neste trabalho - que tem foco na contextualização da química e no impacto que essa atividade pode ter na preservação patrimonial e na alfabetização científica - propôs-se, elaborou-se, aplicou-se e avaliou-se uma atividade que objetivou promover o ensino de química por meio do patrimônio cultural ao mesmo tempo em que suscitou a preservação patrimonial e a alfabetização científica na área da química aplicada a bens culturais. $\mathrm{O}$ trabalho, desenvolvido por equipe interdisciplinar, fundamentou-se na integração de metodologias de ensino em ciências e de educação para o patrimônio, contemplando o conceitual químico e as implicações sociais e culturais envolvidas no patrimônio. Como resultados, os alunos assimilaram conteúdos de química e demonstraram a apropriação da relação entre ciência e patrimônio. Passaram também a melhor reconhecer o valor e o significado de patrimônio cultural, identificando-se como agentes de preservação e demonstrando o reconhecimento de suas responsabilidades sociais, culturais e ambientais no processo de preservação.
\end{abstract}

Palavras-chave: Preservação cultural. Patrimônio cultural. Alfabetização científica. Ensino de química.

\begin{abstract}
In this paper - focusing on the contextualization of chemistry and on the possible impact of this activity on heritage preservation and scientific popularization - an activity was proposed, elaborated on, applied and evaluated that aimed to promote the teaching of chemistry through cultural heritage alongside the promotion of heritage preservation and scientific popularization in the field of chemistry applied to cultural heritage. The work, developed by an interdisciplinary team, was based on the integration of science teaching and heritage education methodologies, dealing with chemical concepts and the social and cultural implications involved in cultural heritage. In terms of results, the students assimilated chemistry contents and demonstrated the appropriation of the relation between science and heritage. They also recognized better the value and meaning of cultural heritage, identifying themselves as agents of preservation and demonstrating the recognition of their social, cultural and environmental responsibilities in the preservation process.
\end{abstract}

Keywords: Cultural preservation. Cultural heritage. Science literacy. Chemistry teaching.

${ }^{1}$ Universidade Federal de Pelotas (UFPel), Departamento de Museologia, Conservação e Restauro, Pelotas, RS, Brasil. E-mail: tspuglieri@ufpel.edu.br

${ }^{2}$ UFPEL, Centro de Ciências Químicas Farmacêuticas e de Alimentos, Pelotas, RS, Brasil.

${ }^{3}$ UFPEL, Faculdade de Educação, Pelotas, RS, Brasil. 


\section{Introdução}

O ensino de química no Brasil se depara frequentemente com desafios associados ao não reconhecimento de sua aplicabilidade no cotidiano, como em aplicações tecnológicas, ambientais, sociais, políticas, econômicas e históricas. Como consequência, muitas vezes essa disciplina se torna pouco atrativa ou interessante. Pensando nisso, uma série de trabalhos tem sido desenvolvida com o objetivo de contextualizar a química no cotidiano dos alunos.

Segundo Wartha, Silva e Bejarano (2013), essa contextualização deve ser tida como um recurso pedagógico para contribuir com a construção de conhecimentos e com a formação de capacidades intelectuais superiores. Segundo os autores, as propostas de abordagem do cotidiano intencionam também a compreensão de um contexto além do conceitual, passando por aplicações sociais e ambientais, por exemplo, e devem permitir que o indivíduo analise, entenda e julgue sua participação num contexto físico e social, onde também é necessário pensar nos espaços vividos, percebidos e concebidos, uma vez que é nesses espaços que acontece a vida cotidiana.

Neste sentido, o uso de temas do cotidiano no ensino de química pode promover impactos positivos não só no ensino, mas também na área abordada como, por exemplo, na área de patrimônio cultural; é possível que a contextualização da química por meio de bens culturais melhore a compreensão dessa disciplina ao mesmo tempo que, dependendo da metodologia utilizada, promove a preservação do patrimonial.

O patrimônio artístico, histórico e cultural pode ser dividido em, pelo menos, bens culturais materiais e imateriais. Os bens materiais (pinturas, esculturas, desenhos, edificações etc.), como o próprio nome diz, são constituídos por matéria, de modo que sua produção, degradação, preservação e investigação envolvem fenômenos e conceitos químicos que no exterior já vêm sendo usados no ensino de química (DEL FEDERICO et al., 2013; GOODALL, 2006; MAYHEW et al., 2014; PEREIRA; PAIXÃO; CACHAPUZ, 2006; RESS, 2014; SEERY, 2013). Esses trabalhos, frequentemente, e muitas vezes de modo indissociável, envolvem conteúdos que promovem também a alfabetização científica no contexto da química aplicada a bens culturais. No Brasil, até onde temos conhecimento, poucos trabalhos têm atuado nesta interface entre ensino, química e patrimônio (ARGOLO; COUTINHO; CHACON, 2012; CARVALHO; PINTO NETO, 2016).

Por si só, o uso de bens culturais para ensino e alfabetização científica pode surtir pouco ou nenhum efeito na preservação patrimonial, mas, quando é feito junto da educação para o patrimônio, esse objetivo pode ser atingido. Educar para o patrimônio, uma das especialidades da área da Museologia, implica ofertar ao público a possibilidade de interpretar e atribuir diversos sentidos a determinado bem (GRINSPUM, 2000), deslocando-se, metodologicamente, a ênfase do objeto para as pessoas, que, ao se apropriarem dos bens, os valorizam, compartilham e promovem sua preservação.

A preservação de bens culturais, como se pode notar, é uma área inter e transdisciplinar, que envolve, por exemplo, ciências naturais e ciências humanas. Nesse cenário, a conservação, a arte, a história e a química são áreas indissociáveis quando consideradas ações de preservação patrimonial, mas, especialmente no Brasil e em seu ensino disciplinar, a integração dessas áreas é um grande desafio.

Considerando o exposto e a importância da noção de inter e transdisciplinaridade na formação do ser humano, este trabalho teve como objetivo a proposição, elaboração, aplicação 
e avaliação de uma atividade para promover o ensino de química por meio de abordagens patrimoniais e ao mesmo tempo promover a preservação patrimonial e a alfabetização científica pelo ensino de química. Transpassam-se, assim, as barreiras da convencional disciplinaridade pela atuação de uma equipe formada por profissionais da química, história, arte e museologia. Alunos do ensino médio de uma escola da rede pública formaram o público alvo deste trabalho, que contemplou tanto o conceitual químico quanto as implicações sociais e culturais envolvidas no patrimônio. Até onde sabemos este é o primeiro trabalho que discute de forma explícita a ação conjunta dessas duas metodologias (ensino de química e educação para o patrimônio) com os objetivos supracitados, tanto em cenário nacional quanto internacional.

O trabalho segue dividido em duas partes: (1) Patrimônio e alfabetização científica, e (2) Estudo de caso. A primeira parte tem por intenção contextualizar para o leitor: (i) educação para o patrimônio; (ii) instituições museais e patrimônio histórico; e (iii) interdisciplinaridade e alfabetização científica. A segunda parte tem a finalidade de apresentar o estudo de caso conduzido com alunos do ensino médio.

\section{Patrimônio e alfabetização científica}

\section{Educação para o patrimônio}

A educação para o patrimônio, como o nome sugere, é aquela que se faz tendo como foco o patrimônio. Para Cabral (2002, p. 5) o patrimônio é “[...] meio de comunicação e campo de educação [...]", que pode e deve ser objeto de ações educativas que contribuam para a mudança social. Se de certa forma todo museu é histórico, talvez toda educação digna deste nome seja para e por meio do patrimônio, a qual se faz, particularmente, considerando o repertório que o sujeito traz consigo, o conhecimento produzido ao longo do tempo, os objetos, saberes, monumentos, ofícios e edificações que o cercam.

As ações educativas desenvolvidas para o patrimônio têm sempre um duplo sentido: favorecer o acesso ao bem patrimonial - seja um museu, um monumento ou um ato de fazer, de um patrimônio imaterial, por exemplo, proporcionando proximidade, pertença e ampliação do repertório cultural do participante - e favorecer a preservação do patrimônio, já que é preciso conhecer para preservar. É neste sentido que Horta, Grunberg e Monteiro (1999, p. 6) escrevem:

O diálogo permanente que está implícito neste processo educacional estimula e facilita a comunicação e a interação entre as comunidades e os agentes responsáveis pela preservação e estudo dos bens culturais, possibilitando a troca de conhecimentos e a formação de parcerias para a proteção e valorização desses bens.

Usualmente as ações educativas nessa área são apresentadas como não formais, diferentemente da escola, onde a educação é formal por excelência. O objetivo do trabalho aqui apresentado, contudo, é justamente apontar as complementaridades entre estas duas instâncias: o ensino de química é potencializado na interação com o patrimônio, que neste processo cumpre uma função social e ganha importância para os participantes que passam a lhe atribuir valor. 
A articulação entre o ensino escolar da Química e o bem patrimonial - neste caso as esculturas em metal fundido da principal praça da cidade (Praça Coronel Pedro Osório, em Pelotas) - carregado de memórias, técnicas de produção, arte, valores e possibilidades de sentido, proporciona aos participantes a oportunidade de vivenciar e assim aprender, enxergando, por exemplo, seus processos de degradação e transformando informação em construção de conhecimento.

Ainda, há uma dimensão lúdica no processo que deve ser valorizada, pois não há nenhuma razão para que o aprender não seja divertido. De acordo com Wajskop (1995), a brincadeira se faz presente na vida adulta das pessoas na forma de jogos, e "[...] o tocar e o abraçar, olhar nos olhos e rir juntos pode ser importante em um processo de pluralidade cultural, desaceleração de estereótipos sexuais e maior compreensão das necessidades especiais $[\ldots] ”$ (DOHME, 2008, p. 14).

\section{Instituições museais e patrimônio histórico}

Compreender, contemporaneamente, o papel dos museus implica fazer um exercício de digressão. Ao observar sua trajetória institucional e suas conexões com o patrimônio, notamos que sua origem assenta-se na Revolução Francesa. Nesse período, os referenciais patrimoniais, abrigados ou não pelos museus, serviram como símbolo da formação dos EstadosNação, tendo como nascedouro o ideário iluminista (CHAGAS, 2005). Os patrimônios recém -inventados, e pretensamente protegidos por forte aparato jurídico e técnico (CHOAY, 2001), foram utilizados como estandartes das "[...] grandes narrativas, onde se exalta a construção grandiloquente e épica do nacional através dos grandes feitos e da participação da nação no concerto universal" (SANTOS; CHAGAS, 2002, p. 200).

Os traços históricos do conceito de patrimônio, e suas apropriações contemporâneas, já foram ricamente delineados por diversos pesquisadores, em trabalhos como os de Funari e Pelegrini (2006), Regina Abreu (ABREU, 2007), Dominique Poulot (POULOT, 2009), José Reginaldo Gonçalves (GONÇALVES, 2002, 2005), dentre outros, que articulam os conceitos de museu e patrimônio. $\mathrm{O}$ estrato dessa produção pode ser sintetizado em algumas imagens, por vezes obsoletas, mas que ainda são permeabilizadas no escopo das políticas públicas para o patrimônio, quais sejam: o patrimônio como herança, o patrimônio como símbolo do Estado e o patrimônio como resultado de atos jurídicos. No mesmo compasso, os museus chegam ao século XXI ainda com o ranço de serem lugares defasados, enfadonhos e desconectados das dinâmicas sociais. Somado a isso, ainda parece difícil imaginar manifestações museológicas que não estejam aprisionadas em seus contornos institucionais (o museu-lugar/templo).

Não por menos, Huyssen (1994, p. 50) destaca que "Tanto para Baudrillard como para Jeudy, a musealização é precisamente o oposto da preservação: é o mesmo que matar, congelar, esterilizar, 'de-historicizar' e 'de-contextualizar'”. Os caminhos pretendidos, na experiência que motiva este artigo, guiaram a uma rota diametralmente oposta, buscando observar, como ficará mais claro na discussão da atividade, a Praça, as estatuárias, o chafariz - enfim, o lugar de ação - por meio de um prisma interdisciplinar. Endereçam-se a essas referências patrimoniais questões que fazem seus partícipes refletirem o presente, mais do que evocarem valores monolíticos que as engessam no passado. Ao colocar os objetos em contexto, e em consonância com problemas contemporâneos e questões que interessam também à academia 
(no caso, a Química), a ideia foi indicar que é possível lançar novos olhares ao que parece taxidermizado na categoria de patrimônio histórico.

A lente pela qual observa-se o patrimônio se alicerça nas noções contemporâneas de museu e patrimônio. No campo dos museus, parece claro que seus contornos epistemológicos vêm se estendendo de forma bastante profícua, assim como as formas de abordar os patrimônios. Para além das funções tradicionais de recolha, documentação, conservação e exibição, a área vem se ocupando de forma intensiva em observar a relação travada entre os sujeitos e seus referenciais patrimoniais.

De acordo com Bruno (1996), a Museologia abre horizontes de interlocução com as diversas áreas do conhecimento, notadamente com as Ciências Humanas, oferecendo uma aproximação sistemática com a sociedade do presente, em dois principais níveis: " 1 identificar e analisar o comportamento individual e/ou coletivo do homem frente ao seu patrimônio. $2^{\circ}$ desenvolver processos técnicos e científicos para que, a partir dessa relação, o patrimônio seja transformado em herança e contribua para a construção das identidades" (BRUNO, 1996, p. 10). A mesma autora identifica que museologia, em sua faceta aplicada, tem como objeto central a compreensão da relação entre Homem (público/comunidade/sociedade) e Objeto (referência cultural/indicador da memória) em um Cenário (instituição/espaço construído/ território de intervenção) (BRUNO, 2013-2014).

Para além da síntese proposta pela autora, importa grifar um aspecto que não pode passar despercebido: a ideia de que a Museologia, e sua configuração acional (o museu), não se restringe aos referenciais de patrimônio que residem no interior dos museus, alargando seu campo de visão e atuação para além das cercanias institucionais e formalizadas. Em rota convergente, pelo olhar fenomenológico do campo museal, Scheiner (1999) compreende que o museu, em seu sentido etimológico, guardaria mais relação com o termo Mousáion (pelas Musas) na medida em que o museu, como manifestação da memória, dispensaria o espaço edificado; dependeria, sim, de um espaço intelectual possível de presentificação das ideias, de manifestação da memória (SCHEINER, 1999).

Transpondo as ideias supramencionadas para o contexto da ação, na Praça Coronel Pedro Osório, o que se buscou com esta prática foi instigar a relação intersubjetiva entre os participantes da atividade e os referenciais patrimoniais, em um território delimitado de intervenção (a Praça). Mais do que resgatar seus valores originais (se é que isso é possível), a ação redundou em provocar o olhar museal sobre aqueles bens, para muitos apenas símbolo de um passado glorioso que não se quer deixar esquecer. O olhar multifocal proposto permitiu observar o patrimônio por ângulos geralmente obliterados pelas lógicas hegemônicas de políticas públicas para o patrimônio. Implica dizer que, para um mesmo patrimônio, há uma multiplicidade de interpretações e usos - e aqui incluem-se os usos acadêmicos e para a educação formal. Em sentido análogo com a ideia de ativação patrimonial (PRATS, 2005) ${ }^{4}$, instigou-se com a ação uma releitura sobre o patrimônio, em que o olhar museológico e os lugares de atuação

\footnotetext{
${ }^{4}$ Para Llorenç Prats, o sentido da patrimonialização redunda na qualidade valorativa do patrimônio e deve ser analisada em situação. $\mathrm{O}$ valor patrimonial não seria imanente, mas fruto de ativação. A ativação do patrimônio, e seus efeitos sociais, dependem, portanto, das diferentes manifestações dos poderes políticos, mas fundamentalmente de negociação com outros poderes factuais e com a própria sociedade.
} 
do museu " $[. .$.$] deve[m] ser compreendido[s] do ponto de vista conceitual e não institucional"$ (CHAGAS, 1994, p. 57).

Conforme alerta Choay (2001), o patrimônio não sobrevive à margem do exercício da memória e da cultura de determinada população. Em outras palavras, assumimos como plataforma a ideia de que o patrimônio que não é reconhecido pelo grupo social, e, portanto, não ocupa um lugar na memória afetiva daquele grupo, corre o risco de ser esquecido e desvalorizado. A amnésia social, desse modo, concorre com todos os demais riscos atribuídos ao patrimônio, como saques e vandalismos, além da própria ação do tempo. Escusado será dizer que as políticas de patrimônio dissociadas das dinâmicas sociais, que as deveriam alimentar e reproduzir, redundam em letra-morta; a patrimonialização, em termo, não garante a preservação do bem cultural. E mesmo que implique na preservação estritamente material do bem, é ineficaz, sozinha, para manter sua vitalidade semântica, sua ressonância social.

A orientação da práxis patrimonial proposta neste artigo alinha-se à denominada museologia social que, em síntese, compreende o patrimônio em negociação entre os discursos oficiais, autoridades científicas e a sociedade. Trata-se da possibilidade de gerar novos sentidos e novas leituras mesmo que os referenciais de patrimônio tenham seu valor aparentemente fixo. Motivado pela própria expansão do conceito de patrimônio, o museu ativo desloca seu interesse de objetos frios para as dinâmicas sociais. Em outros termos, implica a adequação das práticas museológicas aos condicionalismos da sociedade contemporânea (MOUTINHO, 1993), que, por sua vez, pode gerar como efeito novas demandas patrimoniais, local, regional ou nacionalmente.

\section{Interdisciplinaridade e alfabetização científica}

Desde as últimas décadas do século XX vêm se tornando cada vez mais evidentes as dificuldades impostas por uma forma de produzir, estruturar e difundir conhecimentos, que é pautada na compartimentalização dos saberes e impulsiona o surgimento de especialidades cada vez mais monoativas, ampliando o afastamento de suas ações conjuntas.

A ciência contemporânea, contudo, considerando a necessidade de lidar com questões complexas e presentes nas interfaces dos diversos saberes, tem atuado cada vez mais na interdisciplinaridade, como ocorre na Ciência da Conservação e na Ciência do Patrimônio. A inconsistência do modelo disciplinar, por exemplo, é atestada por Brandão (2015, p. 2), ao mencionar o caso exemplar da dificuldade que a Física encontra diante dos desafios relacionados ao campo da termodinâmica, tendo assim que se imbricar nos domínios da Química, em diferentes escalas.

Para entendermos o que é a interdisciplinaridade, precisamos primeiro compreender a multidisciplinaridade. Segundo Domingues (2012, p. 15),

[...] o multidisciplinar consiste na justaposição das disciplinas e sua natureza é essencialmente aditiva, não integrativa (p. 56) [sic]: de fato, pode-se dizer, a justaposição é mais do que colocar lado a lado, pois o que é buscado é a aproximação das disciplinas e o compartilhamento das informações [...].

Já “[...] o interdisciplinar, por sua vez, consiste na cooperação das disciplinas, está fundado em genuínos grupos de trabalho (team work) e sua natureza é integrativa.” (DOMINGUES, 
2012, p. 15). A rigor, trata-se de procurar delinear, na percepção de González de Gómez (2017), metaníveis de circulação de saberes, no interior dos quais tais denominações terminológico-conceituais dizem respeito, em última análise, a formas pluralistas de construção de conhecimento.

Vale destacar ainda, um pouco mais a fundo, que a dinâmica do sistema de construção e circulação de conhecimentos interdisciplinares é denominada por Law e Mol (2002) como "complexidade", podendo ser representada, de acordo com Klein (2004), pela metáfora da rede, em suas relações de pluralidade, horizontalidade e interação. $\mathrm{Na}$ prática, o paradigma da hibridização, além de consolidar negociações dialógicas e localizadas ${ }^{5}$ acerca dos sentidos e significados dos saberes e de suas próprias práticas de produção, responde de forma mais adequada e consistente às exigências impostas pela realidade sociocultural complexa da qual não se desvencilha a ciência.

Fundamental acentuar que existe uma intrínseca e profunda ligação entre esses arranjos colaborativos e a própria tese da complexidade, que deixa de ser expressa, dentre outros contextos, na relação entre as ciências duras e as humanidades, em razão de ser negligenciada dentro da estrutura tradicional de ensino. Ao sinalizar-se, portanto, o potencial do ensino da química como instrumento provocador do interesse pela preservação do patrimônio cultural, não se pode esquecer que está implicado nesta rede um rol praticamente imensurável de interagências, que só podem ser adequadamente acercadas a partir de abordagens que não se prendem às amarras impostas pelo arcabouço disciplinar.

Coloca-se ênfase na ciência aqui por ser um exemplo da necessidade de abordagens multi, inter e transdisciplinares, e pelo fato de os conceitos científicos serem também utilizados na educação para a extroversão do conhecimento, como apontado anteriormente para a química e o patrimônio. No que diz respeito especificamente à alfabetização científica, podem-se destacar três eixos estruturantes, de acordo com Sasseron e Carvalho (2011, p. 75-76, grifos do autor):

[...] compreensão básica de termos, conbecimentos e conceitos científicos fundamentais $[\ldots]$

[...] compreensão da natureza das ciências e dos fatores éticos e politicos que circundam sua prática [...];

[...] entendimento das relaçooes existentes entre ciência, tecnologia, sociedade e meio-ambiente.

As propostas didáticas que surgirem respeitando esses três eixos, portanto, devem, particularmente, ser capazes de promover o início dessa alfabetização, visto que terão criado

\footnotetext{
${ }^{5}$ Termo empregado aqui com base no conceito de saberes localizados proposto por Haraway (1995), que em oposição à noção universalista, indica que ciência e os conhecimentos por ela produzidos são produções sóciohistóricas, portanto, contingentes e situadas.

${ }^{6}$ Baseamo-nos aqui no conceito de rede em Latour (1994), no qual se destacam a existência de fluxos, alianças, movimentos, e não se criam vínculos prévios entre elementos estáveis e definidos, de maneira que as relações são constantes entre os agentes envolvidos.
} 
oportunidades para trabalhar problemas envolvendo a sociedade e o ambiente, discutindo, concomitantemente, fenômenos do mundo natural associados à construção do entendimento sobre os próprios fenômenos e aos empreendimentos gerados com base em tal conhecimento (SASSERON; CARVALHO, 2011).

\section{Estudo de caso}

O estudo de caso/atividade é apresentado em duas partes, sendo a primeira o Desenvolvimento da atividade e a segunda a Avaliação da atividade.

\section{Desenvolvimento da atividade}

O planejamento da atividade baseou-se em outras experiências da literatura (MARINE, 2013), sendo que, embora tratem de viagens e intercâmbios, boa parte de seu conteúdo pode ser aplicado a saídas de campo. Propôs-se, com isso:

1. identificar objetivos e público alvo;

2. desenvolver proposta curricular;

2.1. definir tópico (seleção de possíveis abordagens químicas dentro da área de bens culturais);

2.2. identificar um bem cultural, ou bens culturais, que apresente interesse histórico-social e que seja compatível com a abordagem química desejada;

2.3. definir os objetivos de aprendizagem.

3. estabelecer contato com a(s) instituição(ões) responsável(is) pelo(s) bem(ns) cultu$\operatorname{ral}($ is $)$;

4. identificar o acesso a equipamentos;

5. discutir a proposta com o chefe de departamento, colegas e/ou outros;

6. identificar e contatar palestrantes convidados;

7. preparar a metodologia e a atividade considerando química, patrimônio, preservação patrimonial e alfabetização científica;

8. desenvolver a atividade.

O objetivo geral da atividade foi promover o ensino de química por meio de abordagens patrimoniais e, ao mesmo tempo, a preservação patrimonial pelo ensino de química e alfabetização científica na área de química aplicada a bens culturais. Os objetivos específicos e impactos esperados se desdobraram em:

1. desenvolver atividade interdisciplinar com a participação de professores de diversas áreas do conhecimento (química, artes, história e museologia) para promover a interdisciplinaridade no ensino médio e possibilitar aos alunos o reconhecimento de sinergia; cultural;

2. estimular alunos do ensino médio a reconhecerem e se apropriarem do patrimônio

3. incentivar alunos do ensino médio a promoverem a preservação patrimonial;

4. discutir a importância e aplicabilidade de investigações científicas em bens culturais; 
5. proporcionar ferramentas para um melhor entendimento de conteúdos associados à disciplina da química.

Especificamente sobre o tópico de química a ser abordado na atividade, considerouse um daqueles dentro da degradação de bens culturais, que foi a corrosão metálica, especialmente devido ao grande patrimônio metálico presente na cidade de Pelotas. Sobre a identificação de um bem cultural, ou bens culturais, que apresente interesse histórico-social e que seja compativel com a abordagem química desejada, optou-se pelas obras presentes na Praça Coronel Pedro Osório, por esta apresentar um conjunto de mais de uma dezena de esculturas e objetos metálicos.

Desenvolvendo-se os demais itens anteriormente apontados e considerando-se os objetivos do projeto, a proposta foi então organizada da seguinte forma:

1. recepção dos alunos na Praça Coronel Pedro Osório;

2. primeiro contato com o espaço museal da Praça;

3. conversa sobre patrimônio e museu;

4. conversa sobre história e história da arte;

5. conversa sobre processos e agentes de degradação;

6. segundo contato com o espaço museal da Praça;

7. aula sobre corrosão metálica com enfoque em bens culturais;

8. alfabetização científica;

9. visita aos cursos de Bacharelado em Museologia e em Conservação e Restauração de Bens Culturais Móveis da Universidade Federal de Pelotas (UFPel);

10. visita ao curso de Bacharelado em Química Forense da UFPel.

$\mathrm{Na}$ recepção foram explicados aos alunos os objetivos da atividade e como ela seria conduzida. Um mapa da Praça (Figura 1) - com a localização de vários de seus monumentos e algumas informações - também foi elaborado e entregue aos alunos, para que o utilizassem durante o primeiro reconhecimento do espaço museal da Praça. Na sequência, os alunos seguiram sozinhos até cada um dos monumentos para observá-los e senti-los de sua própria maneira.

No retorno, uma conversa sobre patrimônio e museu foi conduzida com os alunos por um profissional da museologia. Tentou-se, de modo dinâmico, estimular a autoconstrução sobre o que é patrimônio cultural, para quem e por que esse patrimônio é importante e por que preservá-lo. Dentro desse contexto buscou-se também estimulá-los a pensar em bens culturais presentes em suas diferentes zonas residenciais, resgatando seus significados dentro da sociedade que os circunda e para si próprios.

Visando exemplificar o que é patrimônio cultural, para quem e por que ele é importante e por que preservá-lo, o Chafariz das Nereidas, de 1873, localizado no centro da Praça, foi apresentado aos alunos. Um profissional das artes conversou sobre a história do Chafariz e também sobre a fundição de ferro e sua iconografia e iconologia. Esse Chafariz, além de importante por sua beleza artística, representa atividades cotidianas no século XIX em que as pessoas buscavam água para suas residências, o que permitiu ainda abordar a história da iluminação pública da cidade - com os postes de iluminação que o circundam - e a sua influência na sociedade contemporânea. 
Puglieri, T. S.; Ribeiro, D. L.; Souza, D. M. V.; Gastaud, C.; Yamasaki, A.; Schneid P. S.

Figura 1 - Mapa da Praça Coronel Pedro Osório entregue aos alunos, com a localização de alguns de seus monumentos

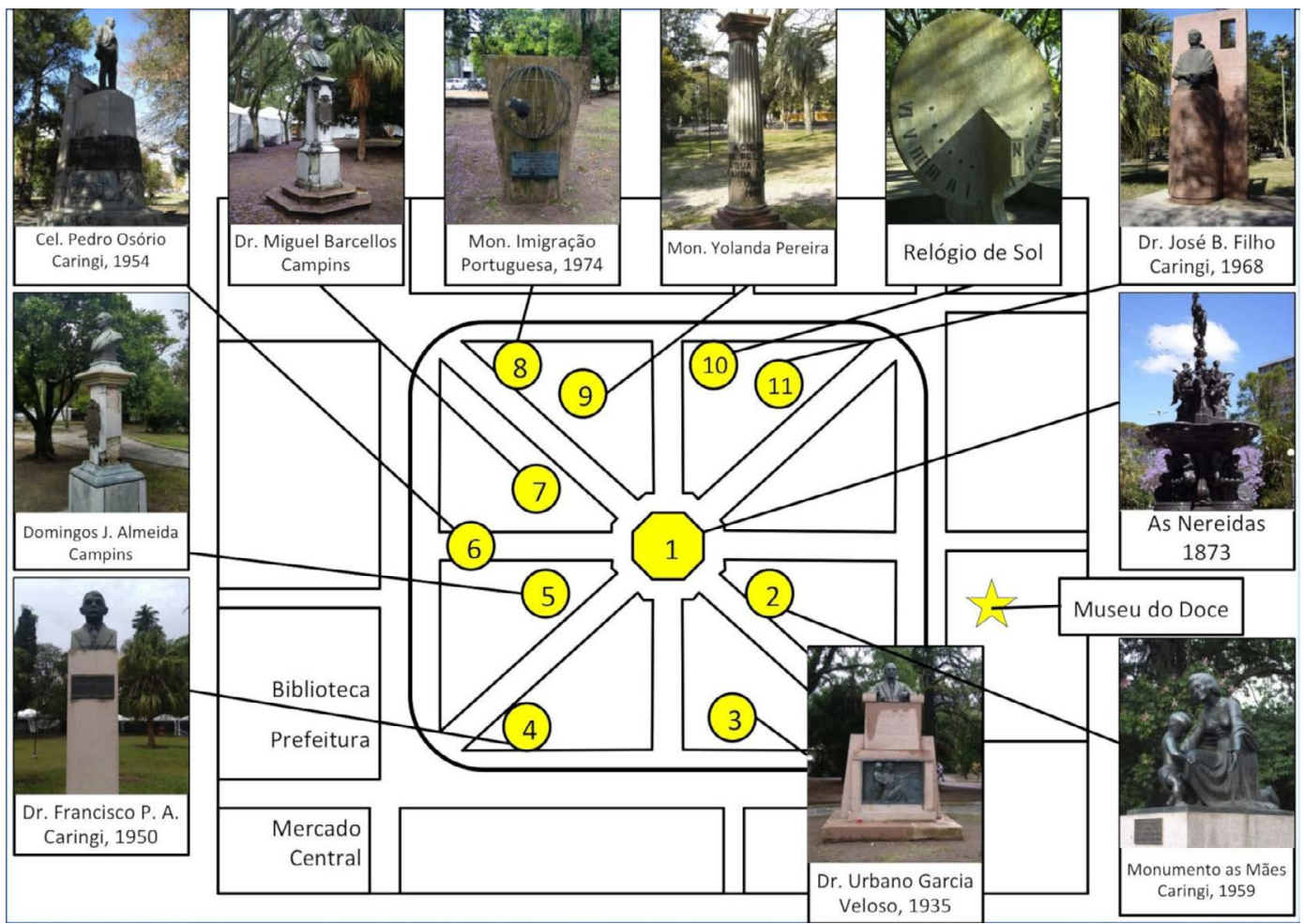

Fonte: elaborado pelos autores a partir de seus arquivos.

Dando continuidade, e introduzindo a presença da química nos bens culturais, ressaltou-se a presença de pontos de corrosão no Chafariz, e um profissional da química (um cientista da conservação, neste caso) passou a conversar com os alunos exemplificando a presença de agentes químicos, físicos e biológicos. Os agentes químicos foram exemplificados pela presença de diferentes produtos de corrosão (Figura 2a), enquanto os agentes biológicos foram exemplificados pela presença de microrganismos (Figura 2b), e os físicos exemplificados tanto pela presença de pequenas trincas e rachaduras quanto por vandalismo (Figura 2c). Nesta etapa foi ressaltado, também, que a presença de um produto de corrosão ou de um microrganismo não necessariamente está relacionada à degradação do bem, pois esses agentes podem estar, em casos específicos, protegendo-os da ação do ambiente. No caso da contextualização da química, por exemplo, apresentou-se o conceito de passivação. 
Figura 2 - Exemplos de agentes químicos na degradação patrimonial

(a)

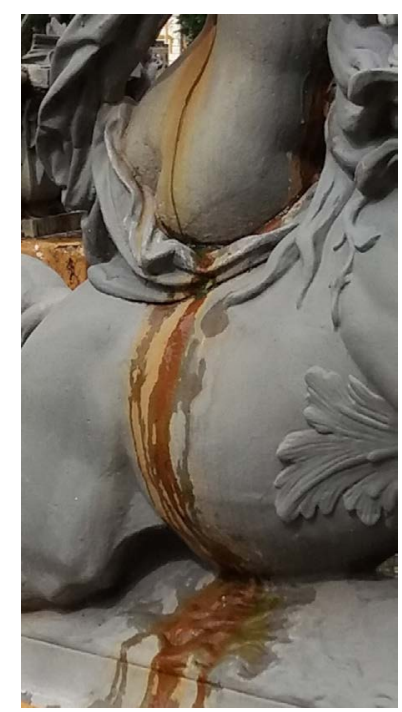

(b)

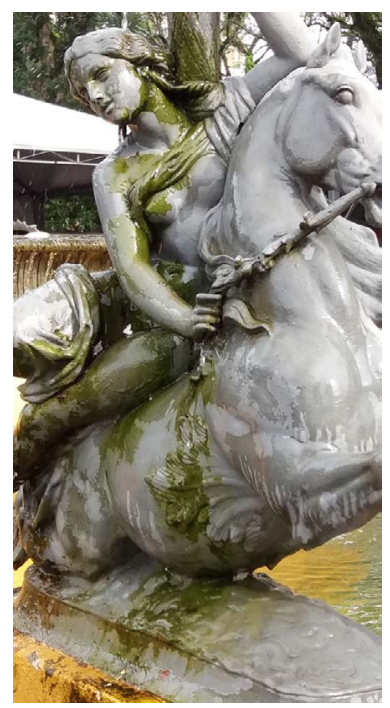

(c)

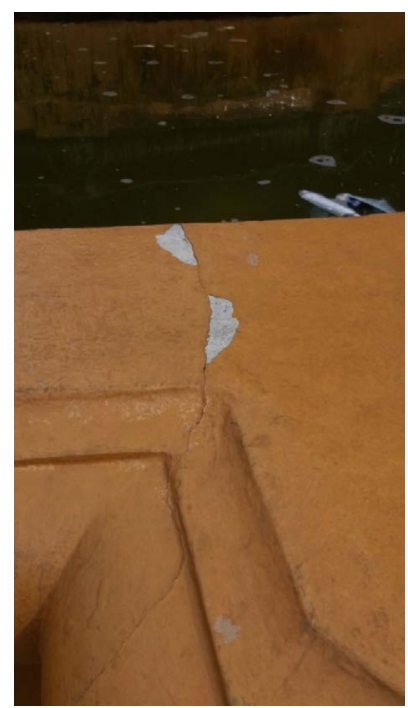

(a) corrosão; (b) agentes biológicos (presença de microrganismos); (c) agentes físicos (trincas/rachaduras). Fonte: elaborado pelos autores a partir de seus arquivos.

Após essa discussão sobre patrimônio - no âmbito da museologia, da história, da arte e da química - os alunos foram convidados a retomarem seus mapas e saírem novamente a caminhar pela Praça. Desta vez foi-lhes entregue um pequeno caderno de anotações, sendo que cada página continha a fotografia de um monumento, uma breve descrição e um espaço para que eles anotassem os potenciais agentes de deterioração (Figura 3). Um espaço maior para anotações foi disponibilizado, pois nesta etapa também foram conduzidas conversas sobre degradação e história dos bens, contando com a colaboração de alunos do Programa de Pós-Graduação em Memória Social e Patrimônio Cultural da UFPel.

Após intervalo para o almoço, as atividades foram retomadas com uma aula conceitual sobre corrosão metálica, com foco nos bens culturais. Na aula foram discutidos os achados dos alunos no segundo contato com o espaço museal da Praça, o conceito de corrosão metálica e os tipos de corrosão (eletroquímica, química e eletrolítica), a influência da acidez na corrosão e chuva ácida, a preservação de um bem cultural metálico (controle de condições ambientais, proteção catódica, revestimentos protetores e inibidores de corrosão) e o processo de corrosão como agente de produção de bens culturais. Discutiu-se, em especial, como os próprios alunos podem preservar os bens culturais. 
Figura 3 - Exemplo do caderno de anotações para observação dos bens culturais após atividades de patrimônio e de observação da degradação
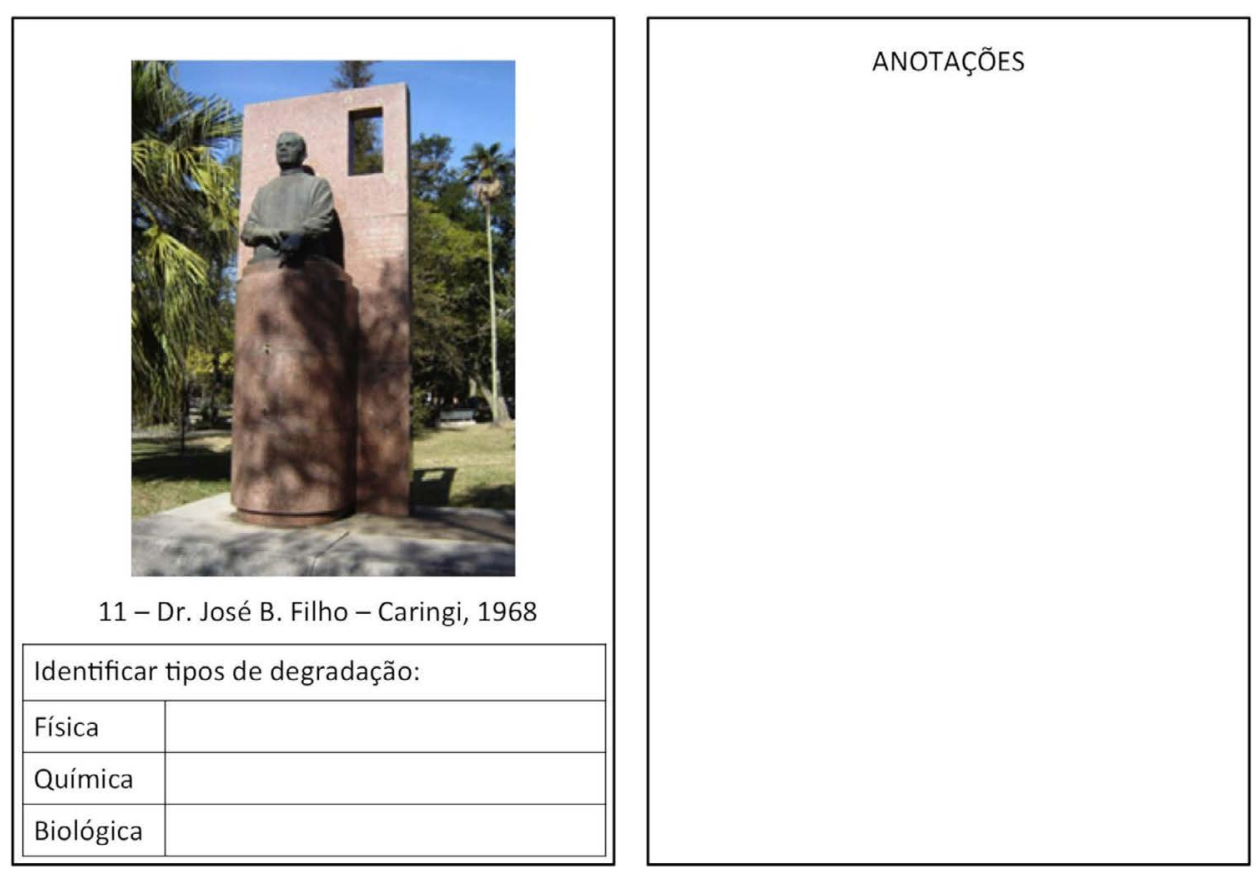

Fonte: elaborado pelos autores a partir de seus arquivos.

Embora toda a aula tenha sido voltada a bens culturais, dá-se destaque ao último tópico, que tratou de como os próprios alunos podem promover a preservação desses bens. Entre os modos de preservação do patrimônio estão as estratégias legais, ou seja, baseadas na ação das leis federais, estaduais e/ou municipais. Uma dessas estratégias é a vigilância, prevista no art. 216 da Constituição Federal de 1988, e que constitui uma ação administrativa de proteção do patrimônio cultural. Tem-se, portanto, que os alunos e a sociedade podem promover a preservação patrimonial pela vigilância. O referido artigo constitucional em seu parágrafo primeiro prescreve que "O poder público, com a colaboração da comunidade, promoverá e protegerá o patrimônio cultural brasileiro, por meio de inventários, registros, vigilância, tombamento e desapropriação, e de outras formas de acautelamento e preservação.” (BRASIL, 2012, p. 124).

Seguindo na relação da química com os bens culturais, foram discutidas com os alunos algumas aplicações científicas no âmbito da química aplicada ao patrimônio histórico e cultural. Os tópicos abordados foram: (i) investigação química de bens culturais para recuperação de informações históricas; (ii) entendimento de processos de degradação para proposição de estratégias de conservação e (iii) investigação química de bens culturais para autenticação (Química Forense). 
Para encerrar a atividade os alunos visitaram laboratórios dos cursos de bacharelado em Museologia, em Conservação e Restauração de Bens Culturais Móveis e em Química Forense da UFPel.

\section{Avaliação da atividade}

O impacto da metodologia e da atividade aqui propostas e aplicadas foi avaliado em relação à aprendizagem conceitual de química e ao reconhecimento, apropriação e noção de patrimônio e preservação. Destaca-se que, de modo a garantir o melhor desempenho possível dos alunos na atividade, esta somente foi realizada depois de os alunos já terem estudado conceitos básicos de oxirredução e eletroquímica. Além disso, considerando o desconhecimento inicial dos alunos sobre a aplicação de química a bens culturais, a professora os alertou sobre o tema em sala de aula, permitindo que já começassem a pesquisar por conta própria.

A avaliação, portanto, consistiu na aplicação de um questionário antes da atividade (questões de 1 a 4) com sua reaplicação uma semana depois (questões de 1 a 8), oferecendo tempo para os alunos assimilarem e discutirem os conteúdos abordados. Com as respostas dos questionários em mãos, foram avaliados o desenvolvimento conceitual e a apropriação de termos antes e depois da atividade, de forma similar a outros trabalhos (FREIRE; SILVA; SILVA JÚNIOR, 2014; MORTIMER et al., 2015; VIDAL; MELO, 2013).

A seguir, o questionário apresentado aos alunos para avaliação da atividade aqui proposta e desenvolvida.

Pergunta 1. Quais os tipos de degradação que ocorrem nos bens culturais?

Pergunta 2. Como você mesmo pode preservar um bem cultural?

Pergunta 3. Qual a relação entre a química e os bens culturais?

Pergunta 4. O patrimônio cultural é importante para você? Por quê?

Pergunta 5. O que é corrosão metálica e quais os tipos de corrosão metálica?

Pergunta 6. Do que depende o processo de corrosão do ferro?

Pergunta 7. Você acha que em nossa atmosfera pode haver a presença de ácidos? Se sim, como?

Pergunta 8. Você acha que a corrosão metálica apenas se relaciona com a degradação dos bens culturais ou também se relaciona com a produção dos mesmos?

Para a primeira pergunta: Quais os tipos de degradação que ocorrem nos bens culturais? foi possível organizar as respostas em dois grupos. O primeiro envolve a ação do homem e o segundo a ação do ambiente, notando-se que antes da atividade os alunos já possuíam conhecimentos sobre os temas, mas, após a atividade, passaram a usar termos mais específicos, como degradação química, física e biológica, microrganismos, bactérias, fungos, algas e plantas. Além disso, notou-se que, com a divisão das ações químicas, físicas e biológicas, os alunos também organizaram melhor seus conceitos e pensamentos.

Com relação à segunda questão: Como você mesmo pode preservar um bem cultural?, as respostas antes da atividade envolveram a denúncia dos atos de depredação, a promoção da manutenção e o ato de não vandalizar. Depois da atividade, contudo, além das respostas anteriores foram acrescentadas estratégias como conscientizar outras pessoas, conduzir procedimentos de restauração por profissionais da área (o conservador-restaurador), evitar a poluição (relacionando-a à chuva ácida), ter respeito pela cultura, promover educação e conduzir a vigilância. 
Nota-se, portanto, que os alunos ampliaram seu conhecimento assumindo responsabilidades sociais, culturais e ambientais.

Para a terceira pergunta: Qual a relação entre a química e os bens culturais?, inicialmente os alunos relacionaram a química com a própria construção do bem, além do uso de produtos para preservação, incluindo limpeza, restauração e conservação. As respostas dadas após a atividade, contudo, mostraram, além das informações já presentes no primeiro questionário, o uso de termos mais específicos e refinados, como oxidação, galvanização, corrosão e sais. Notou-se também a descrição da química como uma ciência, termo que não havia sido usado nas respostas dadas antes da atividade. Além disso, em uma das respostas foi relatada a atuação do químico na investigação ambiental para identificar as causas de degradação, permitindo a proposição de estratégias para conservação-restauração, tema abordado na etapa de alfabetização científica (FARIA; PUGLIERI; SOUZA, 2013).

Na quarta questão: O patrimônio cultural é importante para você? Por quê??, foi unânime a afirmação de que é importante, tanto antes quanto depois da atividade. As respostas dadas pelos alunos deixaram clara sua apropriação do patrimônio, tanto em nível local quanto regional e federal, como pode ser exemplificado pela resposta "Sim, pois é uma característica histórica, da minha cidade, meu país, meu estado". Destaca-se, ainda, que após a atividade as justificativas passaram a também apresentar termos bastante específicos, tais como valor simbólico e identidade: "Sim, porque é simbólico, é uma identidade da nossa região". Além disso, notou-se que pelo menos uma das respostas trouxe também uma apropriação da pesquisa na área do patrimônio: "Sim, com ele conseguimos descobrir coisas novas sobre o passado, sobre a história de seus artistas, de como as pessoas viviam antigamente, além de embelezar um determinado lugar".

$\mathrm{Na}$ quinta questão: $O$ que é corrosão metálica e quais os tipos de corrosão metálica?, a maioria dos alunos definiu corretamente o termo corrosão, em suas diferentes linguagens, e elencou os três tipos (química, eletroquímica e eletrolítica), como abordado em sala de aula (MERCON; GUIMARÃES; MAINIER, 2004). Na questão: Do que depende o processo de corrosão do ferro?, a maioria relacionou o processo às condições ambientais, destacando-se especialmente à presença de oxigênio e água. Na questão: Você acha que em nossa atmosfera pode haver a presença de ácidos? Se sim, como?, os alunos responderam sim e relacionaram a presença de ácidos a poluentes e chuva ácida.

Sobre a oitava e última pergunta: Você acha que a corrosão metálica apenas se relaciona com a degradação dos bens culturais ou também se relaciona com a produção dos mesmos?, os alunos relacionaram a corrosão metálica tanto à degradação de bens culturais quanto à sua produção, o que era um dos objetivos da atividade: mostrar que a corrosão não atua somente de maneira negativa nos bens culturais.

\section{Conclusões}

Com a metodologia e a atividade propostas, integrando-se conceitos e práticas das áreas do ensino em ciências e da educação para o patrimônio, pôde-se, concomitantemente, promover o ensino de química, a preservação patrimonial e a alfabetização científica no contexto da química aplicada a bens culturais.

Especificamente sobre química, os alunos assimilaram conceitos de corrosão, relacionando-os ao meio ambiente, aos bens culturais e às ações do ser humano numa esfera mais 
ampla. Neste contexto, passaram a melhor reconhecer o valor e o significado de patrimônio cultural e a se identificarem como agentes de preservação, demonstrando o reconhecimento de suas responsabilidades sociais, culturais e ambientais neste processo. Demonstraram, também, uma apropriação da relação entre ciência e patrimônio, contextualizando a química e a ciência em seu cotidiano e reconhecendo a interdisciplinaridade em suas vidas.

Os efeitos gerados por essa ação são ressonantes e devem ser avaliados em longo prazo. Contudo, abre-se um horizonte considerável para pensar o patrimônio como um lugar de negociação de sentidos, muito mais do que uma entidade cujo valor é objetivo e inconteste. Vislumbra-se que a partir da perspectiva de fusão metodológica o patrimônio seja percebido no plural, contemplando suas múltiplas dimensões - política, econômica, social, científica e, sobretudo, afetiva. A rigor, a preservação patrimonial deve ser pensada dentro da dinâmica social e orientada pelos condicionalismos do presente.

Por fim, o trabalho promoveu formação especializada e material para dar continuidade a tais abordagens na escola envolvida, visto que o desenvolvimento e aplicação da metodologia foram realizados em conjunto com a professora da escola, coautora deste artigo.

\section{Referências}

ABREU, R. M. R. M. Patrimônio cultural: tensões e disputas no contexto de uma nova ordem discursiva. In: LIMA FILHO, M. F.; ECKERT, C.; BELTRÃO, J. F. Antropologia e patrimônio cultural: diálogos e desafios contemporâneos. Blumenau: Nova Letra, 2007. p. 263-286.

ARGOLO, M. I. S.; COUTINHO, L. G. R.; CHACON, E. P. Química e arte: uma articulação mostrada através de mapas conceituais. In: ENCONTRO NACIONAL DE ENSINO DE QUÍMICA, 16., 2012, Salvador. Anais [...]. Salvador: UFBA, 2012.

BRANDÃO, G. S. N. B. Complejidad y sus otros tantos nombres: innovación y arreglos colaborativos. Sistemas Sociales [online], 1 out. 2015. Disponível em: http:/ / sistemassociales.com/complejidad-y-sus-otros-tantos-nombres-innovacion-y-arregloscolaborativos/. Acesso em: 13 fev. 2019.

BRASIL. Constituição (1988). Constituição da República Federativa do Brasil. 35. ed. Brasília: Câmara dos Deputados, 2012.

BRUNO, M. C. O. Musealização da arqueologia: caminhos percorridos. Revista de Arqueologia, Pelotas, v. 26, n. 2, 2013; v. 27, n. 1, 2014. Disponível em: https://bdpi.usp.br/ bitstream/handle/BDPI/49289/bruno.pdf. Acesso em: 10 fev. 2017.

BRUNO, M. C. O. Museologia: algumas idéias para a sua organização disciplinar. Cadernos de Sociomuseologia, Lisboa, v. 9, n. 9, p. 9-33, 1996.

CABRAL, M. Comunicação, educação e patrimônio cultural. In: FÓRUM Estadual de 
Puglieri, T. S.; Ribeiro, D. L.; Souza, D. M. V.; Gastaud, C.; Yamasaki, A.; Schneid P. S.

Museus, 8., 2002, Rio Grande. [Trabalho apresentado no Minicurso Museu e Educação]. CARVALHO, M. A.; PINTO NETO, P. C. O ensino de química e sua contribuição para a valorização da identidade cultural. In: ENCONTRO NACIONAL DE ENSINO DE QUÍMICA, 18., 2016, Florianópolis, 2016. Anais [...]. Florianópolis: UFSC, 2016.

CHAGAS, M. Casas e portas da memória e do patrimônio. In: GONDAR, J.; DODEBEI, V. (org.). O que é memória social? Rio de Janeiro: Contracapa: Programa de Pós-Graduação em Memória Social da UNIRIO, 2005. p. 115-132.

CHAGAS, M. S. No museu com a turma do Charlie Brown. Cadernos de Sociomuseologia, Lisboa, v. 2, n. 2, p. 49-65, 1994.

CHOAY, F. A alegoria do patrimônio. São Paulo: Estação Liberdade: Ed. Unesp, 2001.

DEL FEDERICO, E. D.; KEHLET, C.; SCHAHBAZ, H.; CHARTON. B. Chemistry of Pompeii and Herculaneum: a case study course in chemistry at the interface of ancient technology and archeological conservation. Journal of Chemical Education, Easton, v. 90, n. 2, p. 264-265, 2013. Comunicação apresentada ao ConfChem Conference on Case-Based Studies in Chemical Education, 2012, [Easton].

DOHME, V. O valor educacional dos jogos: jogos e dicas para empresas e instituições de educação. Petrópolis: Vozes, 2008.

DOMINGUES, I. Multi, inter e transdisciplinaridade: onde estamos e para onde vamos?

Pesquisa em Educação Ambiental, Rio Claro, v. 7, n. 2, p. 11-26, 2012. DOI: https://doi. org/10.18675/2177-580X.vol7.n2.p11-26.

FARIA, D. L. A.; PUGLIERI, T. S.; SOUZA, L. A. C. Metal corrosion in polychrome baroque lead sculptures: a case study. Journal of the Brazilian Chemical Society, São Paulo, v. 24, n. 8, p. 1345-1350, 2013. DOI: https://doi.org/10.5935/0103-5053.20130170.

FREIRE, M. S.; SILVA, M. G. L.; SILVA, JÚNIOR, C. N. Análise de Instrumentos de Avaliação como Recurso Formativo. Química Nova na Escola, São Paulo, v. 38, n. 1, p. 33-39, 2016.

FUNARI, P. P.; PELEGRINI, S. C. A. Patrimônio histórico e cultural. Rio de Janeiro: Jorge Zahar, 2006.

GONÇALVES, J. R. S. O patrimônio como categoria de pensamento. In: REUNIÃO ANUAL DA ASSOCIAÇÃO NACIONAL DE PÓS-GRADUAÇÃO EM CIÊNCIAS SOCIAIS, 26., 2002, Caxambu. Anais [...]. São Paulo: Anpocs, 2002.

GONÇALVES, J. R. S. Ressonância, materialidade e subjetividade: as culturas como patrimônios. Horizontes Antropológicos, Porto Alegre, v. 11, n. 23, p. 15-36, 2005. DOI: https://doi.org/10.1590/S0104-71832005000100002. 
GONZÁLEZ DE GÓMEZ, M. N. A ciência da informação no cruzamento de fronteiras. In: MOURA, M. A.; SILVEIRA, F. J. N. (org.). X EDICIC: Anais do Encontro da Associação de Educação e Pesquisa em Ciência da Informação da Ibero-América e Caribe. Belo Horizonte: UFMG, 2017. p. 35-61.

GOODALL, D. C. Ancient coins. Education in Chemistry, London, v. 43, n. 6, p. 165-167, 2006.

GRINSPUM, D. Educação para o patrimônio: museu de arte e escola: responsabilidade compartilhada na formação de públicos. 2000. Tese (Doutorado em Educação) Universidade de São Paulo, São Paulo, 2000.

HARAWAY, D. Saberes localizados: a questão da ciência para o feminismo e o privilégio da perspectiva parcial. Cadernos Pagu, Campinas, n. 5, p. 7-41, 1995.

HORTA, M. L. P.; GRUNBERG, E.; MONTEIRO, A. Q. Guia básico de educação patrimonial. Rio de Janeiro: Instituto do Patrimônio Histórico e Artístico Nacional, 1999.

HUYSSEN, A. Escapando da amnésia: o museu como cultura de massa. Revista do Patrimônio Histórico e Artístico Nacional, Rio de Janeiro, n. 23, p. 35-57, 1994.

KLEIN, J. Interdisciplinarity and complexity: an evolving relationship. Emergence: complexity and organization, Litchfield Park, v. 6, n. 1-2, p. 2-10, 2004.

LATOUR, B. Jamais fomos modernos. São Paulo, Editora 34, 1994.

LAW, J.; MOL, A. (ed.). Complexities: social studies of knowledge practices. Durham: Duke University Press, 2002.

MARINE, S. S. Designing a study abroad course in chemistry: information from three different courses to Europe. Journal of Chemical Education, Easton, v. 90, n. 2, p. $178-182,2012$.

MAYHEW, H. E. et al. Using Raman spectroscopy and surface-enhanced Raman scattering to identify colorants in art: an experiment for an upper-division chemistry laboratory.

Journal of Chemical Education, Easton, v. 92, n. 1, p. 148-152, 2014.

MERCON, F.; GUIMARÃES, P. I. C.; MAINIER, F. B. Corrosão: um exemplo usual de fenômeno químico. Química Nova na Escola, São Paulo, v. 1, n. 19, p. 11-14, 2004.

MORTIMER, E. F. et al. Pesquisa em ensino de química na QNEsc: uma análise de 2005 a 2014. Química Nova na Escola, São Paulo, v. 37, n. esp. 2, p. 188-192, 2015.

MOUTINHO, M. C. Sobre o conceito de museologia social. Cadernos de Museologia, Lisboa, v, 1, n. 1, p. 7-9, 1993.

PEREIRA, M. M.; PAIXÃO, M. F.; CACHAPUZ, A. F. Bridging the gap: from traditional silk dyeing chemistry to a secondary-school chemistry project. Journal of Chemical Education, Easton, v. 83, n. 10, p. 1546, 2006.

POULOT, D. Uma história do patrimônio no ocidente, séculos XVIII-XXI: do monumento aos valores. São Paulo: Estação Liberdade, 2009. 
Puglieri, T. S.; Ribeiro, D. L.; Souza, D. M. V.; Gastaud, C.; Yamasaki, A.; Schneid P. S.

PRATS, L. Concepto y gestión del patrimonio local. Cuadernos de Antropología Social, Barcelona, n. 21, p. 19-20, 2005.

REES, S. W. Chemistry unearths the secrets of the Terracotta Army. Education in

Chemistry, London, v. 51, n. 2, p. 22-25, 2014.

SANTOS, M. S.; CHAGAS, M. S. A vida social e política dos objetos de um museu. Anais do Museu Histórico Nacional, Rio de Janeiro, v. 34, p. 195-220, 2002. Disponível em: http://docvirt.com/docreader.net/DocReader.aspx?bib=mhn\&pagfis=17501. Acesso em 17 fev. 2019.

SASSERON, L. H.; CARVALHO, A. M. P. Alfabetização científica: uma revisão bibliográfica. Investigações em Ensino de Ciências, Porto Alegre, v. 16, n. 1, p. 59-77, 2011.

SCHEINER, T. As bases ontológicas do museu e da museologia. In: ICOFOM LAM 99: VIII Encuentro Regional: Museología, Filosofía e Identidad en América Latina y el Caribe. Coro: Venezuela: ICOFOM LAM, 1999. p. 133-164.

SEERY, M. Saving paper. Education in Chemistry, London, v. 50, n. 2, p. 23-25, 2013.

VIDAL, R. M. B.; MELO, R. C. A química dos sentidos: uma proposta metodológica.

Química Nova na Escola, São Paulo, v. 35, n. 1, 2013.

WAJSKOP, G. O brincar na educação infantil. Cadernos de Pesquisa, São Paulo, n. 92, p. 62-69, 1995.

WARTHA, E. J.; SILVA, E. L.; BEJARANO, N. R. R. Cotidiano e contextualização no ensino de química. Química Nova na Escola, São Paulo, v. 35, n. 2, p. 84-91, 2013.

Artigo recebido em 10/10/2017. Aceito em 19/11/2018.

Contato: Universidade Federal de Pelotas, Departamento de

Museologia, Conservação e Restauro, Rua Almirante Barroso 1202

Pelotas 96010-280, RS, Brasil. 